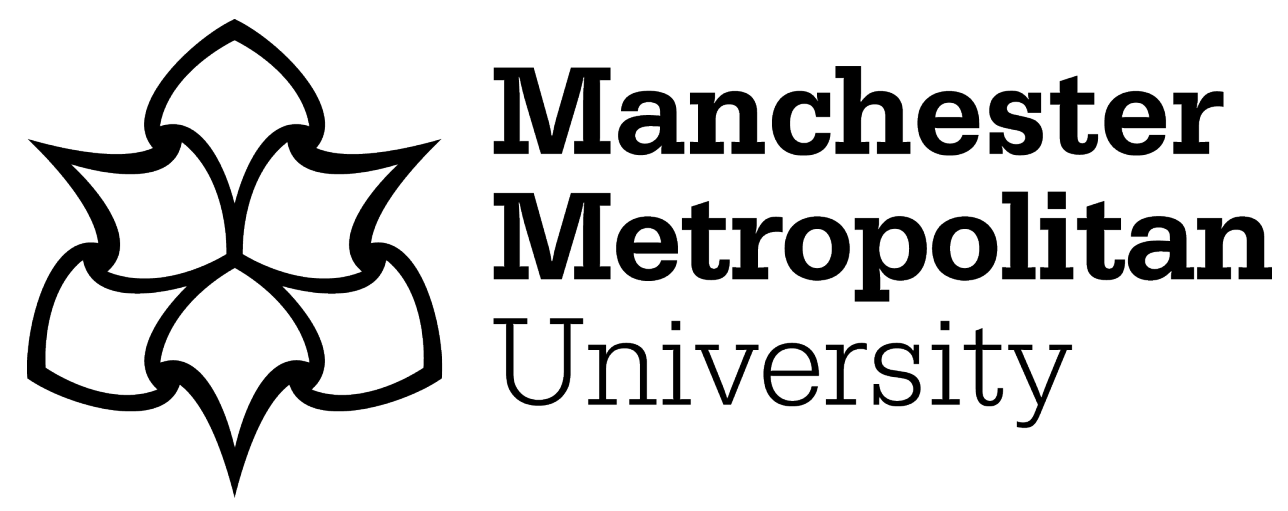

Castellini, MA and Paucar-Caceres, Alberto (2018) A Conceptual Framework For Integrating Methodologies in Management: Partial Results of a Systemic Intervention in a Textile SME in Argentina. Systems Research and Behavioral Science, 36 (1). pp. 20-35. ISSN 1092-7026

Downloaded from: https://e-space.mmu.ac.uk/621920/

Version: Accepted Version

Publisher: Wiley

DOI: https://doi.org/10.1002/sres.2552

Please cite the published version 


\title{
A Conceptual Framework for Integrating Methodologies in Management: Partial Results of a Systemic Intervention in a Textile SME in Argentina
}

\author{
María Alejandra Castellini \\ Facultad de Ingeniería y Tecnología Informática, Universidad de Belgrano \\ Villanueva 1324, Buenos Aires, Argentina \\ Facultad de Ingeniería, Universidad de Buenos Aires \\ Av. Gral. Las Heras 2214, Buenos Aires, Argentina \\ alejandracastellini@gmail.com
}

\author{
Alberto Paucar-Caceres \\ Manchester Metropolitan University Business School \\ All Saints Campus, Oxford Road, Manchester, M15 6BH, UK \\ a.paucar@mmu.ac.uk
}

\begin{abstract}
We report on the partial results of a systemic intervention in which a combined range of methods from classical Operational Research (OR), problem-structuring methods (PSM) and quality management $(\mathrm{QM})$ tools were deployed in a SME in Argentina. Involving a full stakeholders' participation, the intervention allowed the team to appreciate and better understand the features of the problematic situation, its underlying causes and helped the management to define action plans to bring improvements to the organisation. Using the multi-methodological framework proposed by Mingers and Brockelsby for integrating methodologies as a starting point, we advance and test a modified framework that distinguish methodologies/methods by its location in the real world or in the thinking/conceptual world. The article contributes to the current debate on OR multiple paradigmatic practice and follows the trend to combine hard methods, wellknown soft OR tools with some less-known methodologies from the ever increasing portfolio of OR methodologies.
\end{abstract}

Key words: Soft Operation Research, Problem Structuring Methods, Quality Management, Multimethodologies, Systemic Intervention. 


\section{Introduction}

Organizations face every day a growing complexity and constant uncertainty, manifested in the progressive range of problems that require constant attention. This phenomenon affects all organizational levels and all types of organizations, regardless of their size, slowing their development, efficiency and effectiveness. In the last decades, the organizational sciences have tried to reduce this situation by developing methods and methodologies that help to understand these situations, improve them and in some cases solve the continuous variety of organizational problems. Operational Research (OR) has contributed to this task by offering a range of methods and techniques for decision-making assistance.

Until a few years ago, the nature of OR applications were characterized by the use of a particular technique, method or methodology and also by aligning this practice with a particular unique paradigm, i.e. hard, soft or critical. However, in the last two decades professionals and consultants in OR have begun to combine methods, methodologies and techniques from not only one paradigm but from several. This modality of OR is called multi-methodological (MM) practice in a multi-paradigmatic (MP) context. There is evidence in the OR literature that MM and MP have been applied in several organizational contexts (Mingers (1997a, b), Mingers (1999), Mingers (2001), Mingers and Munro (2002). It is interesting to note that this practice is not only circumscribes to large companies but has begun to filter into the contexts of small and mediumsized enterprises (SMEs), Paucar-Caceres, et al (2015), Castellini et al (2017), Pontelli et al (2014), Castellini (2014), Silva Barros et al (2013).

The conceptual framework most commonly used to argue and justify the use of OR methodologies in a multi-methodological way has been the one proposed by Mingers and Brockelsby (1997). This is in the form of a matrix in which the different methodologies to be used are located in line with their best use in any of the four phases of any intervention: Appreciation, Analysis, Assessment and Action. In this paper, we take this matrix as a starting point, and we propose, as will be seen later, a modification by re-situating the range of methodologies according to their belonging to the real world where the problematic situation is located or to the purely conceptual world is to say to the world where they elaborate 'concepts/ models' about the real world. We believe that this correction to Mingers and Brockelsby matrix together with the systemic application reported here are the main contributions of this article to the good multimethodological practice in OR.

This article reports in a systemic intervention in which the in which the original version of the Mingers and Brockelsby framework was applied to bring some management and operational improvement in an Argentine SME. We also report on how the modified version of the above 
framework is applied. In this intervention, a team of five researchers worked closely with people from different levels of the organization directly involved in the problems of this SME. The intervention was for a space of one year. In it, interviews and workshops were developed using soft OR (or PSM) methodologies, hard OR models and quality management (QM) tools, in order to facilitate the implementation of the proposed improvements in the organizational management processes, both strategic and operative level.

The article is structured as follows. After this introduction, in section 2, the theoretical foundations are presented, briefly summarizing the role of soft methodologies in OR and the recent MM practice. In section 3, we introduce the Mingers and Brockelsby framework and propose a modification to it. In section, 4 the application of the proposed scheme is described in some detail and the results of the intervention are discussed. Finally, in section 5 we outline our partial conclusions and suggest an agenda for future research.

\section{Theoretical foundations}

As mentioned in the introduction, the complexity and uncertainty faced by companies affects their development possibilities, their efficiency and effectiveness. Even more when the strategic and management problems in the organizations are not clearly defined, there is no agreement between the stakeholders or stakeholders (people inside or outside the organization that can affect or be affected by this situation), the interest is not necessarily in searching the optimum, but in finding a compromise solution, as indicated by Mingers and White (2010). It is in these cases when Soft OR methodologies have been instrumental in helping to improve the situation considered problematic. In general, an OR team, together with the organization's stakeholders, can work on the analysis of the complex situation and on the proposal of an action plan, taking into account the sociocultural aspects (Yolles, 2010).

\subsection{The multimethodology as a multiparadigmatic practice in OR}

At the beginning of the 90s, an interesting debate arose in OR and the systems communities in the United Kingdom around questions related to the use of more than one methodology (combining them or using parts of them). System academics and systems professionals have been debating the possibilities of using methodologies from different paradigms, recognizing their strengths and weaknesses. There are two approaches that we consider are the most complete in this multi - methodological practice; these are relatively well known in the United Kingdom: (a) critical systems and critical pluralism / complementarism initiated by Flood and Jackson (1991) and lately developed into a so-called "coherent pluralism" by Jackson (1999); and (b) multiparadigm multi- methodology / critical pluralism developed by Mingers (1997a, 1997b). 
Paucar-Caceres (2003) illustrates how to apply these different methodologies from one or different paradigms. This is done using the framework proposed by Mingers (1997a, Mingers and Brocklesby (1997). We affirm that the different methodologies used in this work are framed in option (b) mentioned above, that is, the methodologies to be used do not come from an only one paradigm but from a multi-paradigmatic range, that is, several methodologies or phases of hardsoft spectrum methodologies could be used. Figure 1 illustrates these options, (3) is the closest to the scheme that this article adopts.
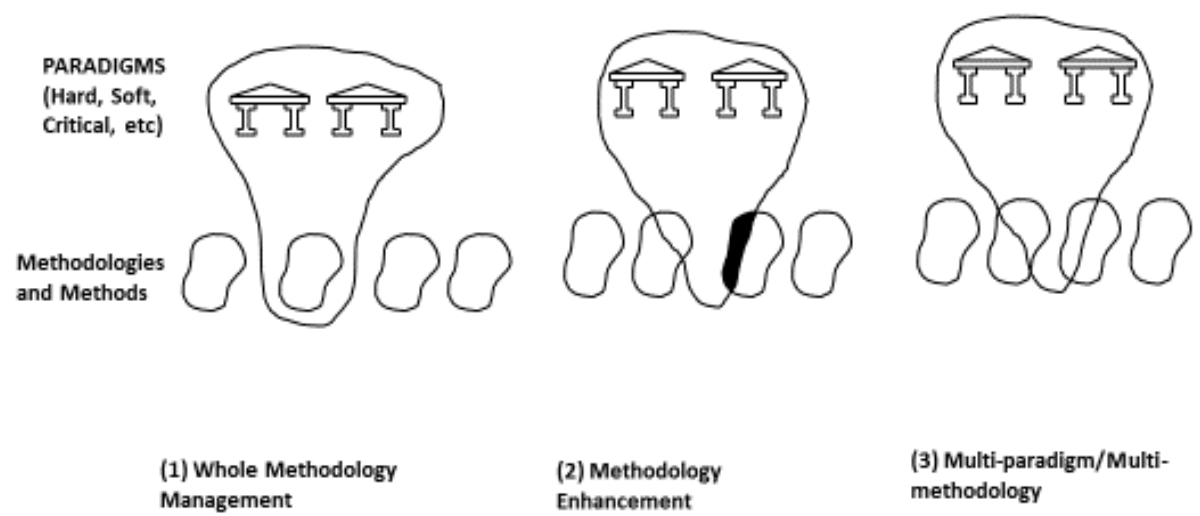
Management methodology

Fig.1. Multi-paradigm types of methodological intervention (from Mingers, 1997a)

\subsection{The emergence of problem-structuring methods and multi-methodological practice}

Problem structuring methodologies (PSM), also called Soft OR, are approximations based on models, which contribute in a constructive and appropriate way not to the solution but to the relief of complex problematic situations.

In general, these methodologies question the optimization paradigm based on a positivist epistemology that is very prevalent for many decades in the administration sciences and they are rather aligned with a learning paradigm and adhere to an interpretive and critical epistemology. In other words, they are methodologies that are characterized by: structuring problems, incorporating conceptual models, considering subjectivity and working for organizations with active participation of their members, as indicated in Rosenhead (2006 and 1989), Rosenhead and Mingers (2001), Vidal (2006). 
Even when in its appearance in the $80 \mathrm{~s}$, soft OR or PSM methodologies were applied in a single and individual way (SSM, SODA), as in Checkland (2000), Eden and Ackermann (2004); in recent years, it has been developed applications with combinations between them and have given way to the practice of MM, in which soft and hard OR are applied in conjunction, as can be seen in Ackermann and Eden (2011), Franco and Lord (2011), Georgiou (2012, 2008), Mingers (2000).

Essentially, as explained in more detail in the following section, the use of multimethodologies in a multi-paradigmatic framework (MM) is an area of OR that focuses on the possibility of combining different methods or part of them, within a particular social intervention, characterized by its complexity, as can be seen in Henao and Franco (2016) and Small and Wainwright (2014)

This combination is based on: (a) Real problematic situations are multidimensional, (b) An intervention is a process carried out in stages that have different tasks and difficulties, which can be better addressed by different methods, (c) combination of methods can provide new insights and make results more reliable.

It is a relatively recent field in which there is special interest in researchers. There are some publications that have been seminal and very influential in the advancement of this practice in several OR forums; one of them that is worth highlighting is the Rosenhead and Mingers book (2001) where the multidimensional world is analysed, according to the version of Habermas (1970) (Action, Verbalization, Emotion) in which the processes of making decision is included. They emphasize the fact that all intervention should be considered as a process and analyse the contributions of each of the soft methods when used in combination with others. It reviews the soft-soft and soft-hard combinations most used until that moment. Likewise another very influential article has been that of Mingers and Brockelsby (1997) in which they define the terminology, the varieties of $\mathrm{MM}$, the reason for its use, based on the multidimensionality of the world (personal, social, material), the intervention as a process, the practice and the feasibility of $\mathrm{MM}$, based on different types of problems: philosophical, cultural and cognitive, as well as the difficulties that may arise in its application, giving a scheme of use and suggesting which of them is appropriate for each phase of intervention, which summarizes in different figures. Kotiadis and Mingers, (2006) emphasize the limitations that may exist in the use of multimethodologies (cultural, cognitive, practical), cite some relevant cases and make explicit a practical case that is the evaluation of a social and health care system, commenting on the relevance of an applied multimethodology (Discrete Event Simulation Model and SSM) and some of the difficulties encountered. Pollack, J. (2009), compares two different ways of applying multimethodologies (in series and in parallel), analysing their advantages and potentialities, considering a real situation in a health system. 


\section{Framework for positioning different methodologies in multi-methodological / multi- paradigmatic practice in $O R$}

In this section we briefly describe the framework for positioning the different OR methodologies developed by Mingers and Brockelsby (1997). As is known, this scheme is based on the ideas expressed by Checkland in his well-known Soft Systems Methodology (SSM). We think that the Mingers and Brockelsby scheme departs somewhat from the base stated by Checkland, that is why in 3.2 we propose to modify it and introduce the initial systemic characteristics of Checkland's approach.

\subsection{Framework for positioning OR methodologies: Outline of Mingers and Brockelsby}

As discussed in the previous section, the scheme proposed by Mingers and Brockelsby (1997) is the one most used to justify and guide the multi-methodological and multi-paradigmatic practice in OR; particularly when it comes to using several PSM in combination.

Table 1 illustrates how Mingers and Brockelsby frames and complements the methods or parts of methods that were selected. This scheme contains two types of dimensions to consider: (1) the 4 stages of the intervention; these appear in the Mingers scheme as 4 "As" (Appreciation, Analysis, Assessment and Action); and (2) three dimensions or worlds that even when, in practice during every intervention, they interact continuously with each other, in the scheme they are considered as discrete, that is, separated; this to help explore the complexity of the problematic situation under consideration. These dimensions are: material, personal and social. 


\begin{tabular}{|c|c|c|c|c|}
\hline & $\begin{array}{l}\text { Phases of multi-meth } \\
\text { (AAAA) }\end{array}$ & dological intervention & & \\
\hline $\begin{array}{l}\text { Dimension } \\
\text { of the } \\
\text { problem }\end{array}$ & $\begin{array}{l}\text { Appreciation of } \\
\text { characteristics of the } \\
\text { problem as to: }\end{array}$ & $\begin{array}{l}\text { Analysis of structures } \\
\text { and restrictions in: }\end{array}$ & Assessment of: & Actions for: \\
\hline Social & $\begin{array}{l}\text { social practices, } \\
\text { power relations }\end{array}$ & $\begin{array}{l}\text { distortions, } \quad \text { conflicts, } \\
\text { interests }\end{array}$ & $\begin{array}{l}\text { ways to change } \\
\text { existing structures }\end{array}$ & $\begin{array}{l}\text { generate } \\
\text { empowerment and } \\
\text { alignment }\end{array}$ \\
\hline Personal & $\begin{array}{l}\text { individual beliefs, } \\
\text { perceptions }\end{array}$ & $\begin{array}{l}\text { differences between } \\
\text { perceptions and rational } \\
\text { positions }\end{array}$ & $\begin{array}{l}\text { conceptualizations } \\
\text { and alternative } \\
\text { constructions }\end{array}$ & $\begin{array}{l}\text { generate } \\
\text { predisposition and } \\
\text { consensus }\end{array}$ \\
\hline Material & physical evidence & causal structures & $\begin{array}{l}\text { physical } \\
\text { structural } \\
\text { alternatives }\end{array}$ & $\begin{array}{l}\text { select and } \\
\text { implement } \\
\text { appropriate } \\
\text { alternatives }\end{array}$ \\
\hline
\end{tabular}

Table 1. Framework for positioning different methodologies in multi-methodological / multiparadigmatic practice in OR (Mingers and Brockelsby, 1997)

\subsection{Proposed framework for positioning OR methodologies for Multi- methodological practice}

Mingers and Brocklesby acknowledge that the different phases a project goes through are based on the work of Checkland (1981, 1999); however, they neglect a fundamental methodological concept since, according to Checkland's argument, in any systemic intervention, (or that pretends to be) the facilitator (or team of facilitators) must clearly distinguish which phases are located in the real world and which in the systemic world. The matrix of Mingers and Brockelsby (1997: 494) identifying its 4 "As" as columns: Appreciation; Analysis; Assessment and Action, says follow the Checkland scheme. This assertion is partially close to that expressed by Checkland who speaks of 4 phases (which expand on the known 7 steps of SSM): Perceive / Select; Predicate; Compare and Take Action. The SSM literature clearly indicates that the second phase Predicate is situated in the conceptual world and the other three in the real world, as illustrated in Figure 2. 


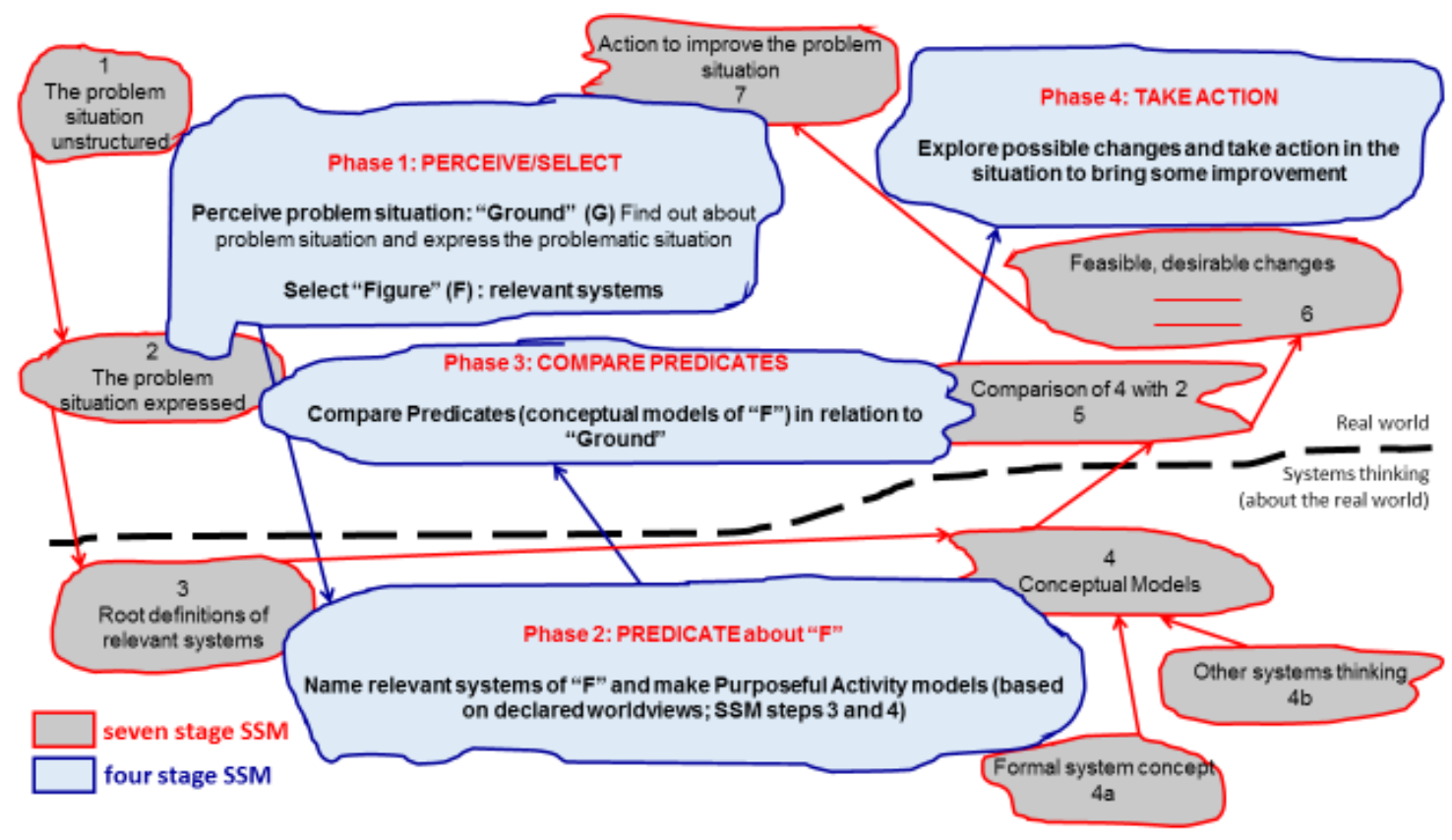

Figure 2. The four Phases of SSM (Perceive, Implicate (Predict), Compare, and Take Action) along with the 7 steps of SSM. [Adapted from Checkland and Tsouvalis (1997), and Paucar-

Caceres and Jerardino-Wiesenborn (2018)]

The Mingers and Brockelsby scheme as it appears in Table 1, in our opinion, deviates crucially from what was proposed by Checkland in two points: (i) it does not distinguish which phases are in the real or conceptual world; (ii) the second phase is called Analysis (of the structures and restrictions of the situation) and not the predicate as Checkland understands it; calling analysis to this phase can make us fall into considering this phase with a deterministic and non-systemic tinge. In this article we intend to correct this by trying to distinguish the positioning (in the real world or conceptual) of the methodologies placed in the matrix.

The modified scheme proposes to re-name two of the phases of the original Mingers scheme: The second one we suggest is called Predicate and the third one is Compare. This is to follow the original Checkland scheme. Worth a digression regarding the name of the second phase: Predicate. This is an activity in Checkland's SSM terminology and essentially refers to the fact that after perceiving the problematic situation, the facilitating team "retires" from the real world to the conceptual world (systems thinking world) and elaborates concepts that try not to predict but make sentences (put predicates to subjects and verbs). These phrases ('root definitions' in the SSM language) preach to the actions that are occurring in the real world. What we are dealing with here is, based on what is perceived as relevant, to elaborate abstract concepts that will later come into play and collate with the real world. In our intervention, we are working on this and it is planned to perform the root definitions of SSM. 
In Table 2 you can see the proposed modification. The columns have been re-named to align them with the SSM phases illustrated in Figure 2. This scheme that we will call "modified Mingers and Brockelsby scheme" differs from the scheme in table 1 with its "Four As: Appreciation; Analysis; Assessment and Take Actions (AAAA) and becomes: Perceive, Predicate, Compare and Action (PPCA).

\begin{tabular}{|c|c|c|c|c|}
\hline & \multicolumn{4}{|c|}{$\begin{array}{l}\text { Phases of the multi-methodological intervention } \\
\text { PPCA }\end{array}$} \\
\hline & Real World & Conceptual World & $\begin{array}{l}\text { Real World } \\
\text { Conceptual world }\end{array}$ & Real World \\
\hline $\begin{array}{l}\text { Dimension } \\
\text { of the } \\
\text { problem }\end{array}$ & $\begin{array}{l}\text { Perceive } \\
\text { A problematic } \\
\text { situation } \\
\text { Select relevant } \\
\text { systems based on: }\end{array}$ & $\begin{array}{l}\text { Predicate } \\
\text { Elaborate predicaments } \\
\text { of relevant areas taking } \\
\text { into account: }\end{array}$ & $\begin{array}{l}\text { Compare } \\
\text { predicates with Real } \\
\text { World }\end{array}$ & $\begin{array}{l}\text { Act } \\
\text { To improve } \\
\text { problematic } \\
\text { situation to: }\end{array}$ \\
\hline Social & $\begin{array}{l}\text { social practices, } \\
\text { power relations }\end{array}$ & $\begin{array}{l}\text { distortions, } \quad \text { conflicts, } \\
\text { interests }\end{array}$ & $\begin{array}{l}\text { ways to change } \\
\text { existing structures }\end{array}$ & $\begin{array}{l}\text { generate } \\
\text { empowerment } \\
\text { and alignment }\end{array}$ \\
\hline Personal & $\begin{array}{l}\text { individual beliefs, } \\
\text { perceptions }\end{array}$ & $\begin{array}{l}\text { differences between } \\
\text { perceptions and rational } \\
\text { positions }\end{array}$ & $\begin{array}{l}\text { conceptualizations and } \\
\text { alternative } \\
\text { constructions }\end{array}$ & $\begin{array}{l}\text { generate } \\
\text { predisposition } \\
\text { and consensus }\end{array}$ \\
\hline Material & physical evidence & causal structures & $\begin{array}{l}\text { physical and structural } \\
\text { alternatives }\end{array}$ & $\begin{array}{l}\text { select and } \\
\text { implement } \\
\text { appropriate } \\
\text { alternatives }\end{array}$ \\
\hline
\end{tabular}

Table 2. Proposed Framework - Mingers and Brockelsby (mod) - Positioning of different methodologies in multi-methodological / multi-paradigmatic practice in OR

Adapted from Mingers and Brockelsby (1997)

\section{Design and implementation of the Multi-Methodological Intervention in an SME textile plant in the Northwest of Argentina}

Starting from the premise that all systemic studies try to contribute to the improvement of the problematic situations that arise in the strategic and management processes of small organizations, in the case of our intervention in the SME, we consider it necessary to know not only its characteristics, but also the context in which it is found. Thus, in this section we describe the context of the intervention, then we outline the design of the combination of applied methodologies and report the execution of the study. 


\subsection{Context}

The textile SME that we report in this study is located in the Northwest extreme of the Argentine Republic, an area with rates of poverty, illiteracy and infant mortality higher than the national averages. From the economic point of view, it is eminently agricultural, contrasting large areas of fields vs. numerous small family subsistence plots. There are few medium or large companies, subsidiaries of international groups and, on the contrary, the number of micro and SMEs is relevant, both in the industrial sector and in the area of trade and services; so its survival contributes significantly to the economy of the region.

Considering these aspects, an interdisciplinary research team from the National University of Salta worked since 1995 on micro and small organizations with the aim of detecting problematic situations and proposing methodologies for their improvement.

The organizations are linked to the University through different channels; either through direct contacts, cameras that group them through electronic media or through the case study activity in OR and QM disciplines. They are informed about the potentialities of the interdisciplinary team and the different contributions of analysis and improvement that can be applied to their strategic and management processes.

Because of these initiatives, approximately 120 interventions have been carried out in micro and small organizations, in which problematic situations were identified and alternatives for improvement were proposed, through different tools of Strategic Management, OR, QM, Economic-Financial Analysis and Environmental Management.

Until 2009, the way of working was as a team of experts in applied research with consultations to the representatives of the organizations at different stages of the research progress. In general, a specific tool was used to model a problematic situation and its approach, while in some cases more than one tool was used, each at different times or for different problems.

Since 2010, the research team of the University of Salta has begun to work interactively with the stakeholders of the organizations: managers, operators, clients, suppliers, working from a specific look to a systemic view of the organization. From this interaction, over the years it become more evident that a combination of methodologies to address their different problems in the social and economic context was needed. The methodological approach and partial results of the intervention in one of these cases, that of an SME operating in the textile sector, are presented in this paper. 


\subsection{Design of the intervention}

This family business has been operating since 2006, its staff consists of five stable people: two in strategy and management, one in administration and two technicians. The main activity is the manufacturing and sale of different types of clothing, including school uniforms.

The first contact with the organization was through a case study developed as part of the OR unit taught in the University of Salta Program, followed by another case study as part of the Quality Management unit. These contacts were the base in which a more fully fletched action research activity was developed led the university interdisciplinary team together with the stakeholders of the organization.

The objective of this action research was to analyse and propose improvements to problematic situations in strategic and management aspects raised by stakeholders. For this and based on the experience of previous case studies, interactive work was prioritized. A combination of methodologies was proposed, from the areas of Soft OR, Hard OR and QM, considering its potential to provide improvements in the different aspects required by the organization.

In the remainder of this section we report the methodologies applied and the results obtained in the SME. It is necessary to clarify that in most of the application we have used the original Mingers and Brockelsby (1997) scheme, where we have located the methodologies that we consider appropriate and relevant in each of the phases. Table 3 summarizes the different tools and methodologies (or parts of them) applied to each dimension and phase of the multimethodological intervention. The tools used are marked in green and those that will be made later are in yellow. 


\begin{tabular}{|c|c|c|c|c|c|c|c|}
\hline Phases & $\begin{array}{l}\text { 1. Appreciation } \\
\text { Mingers and } \\
\text { Brockelsby }\end{array}$ & $\begin{array}{c}\text { 1. Perception } \\
\text { Mingers and } \\
\text { Brockelsby (mod) }\end{array}$ & $\begin{array}{l}\text { 2. Analysis } \\
\text { Mingers and } \\
\text { Brockelsby }\end{array}$ & $\begin{array}{c}\text { 2. Predicate } \\
\text { Mingers and } \\
\text { Brockelsby (mod) }\end{array}$ & $\begin{array}{l}\text { 3. Assessment } \\
\text { Mingers and } \\
\text { Brockelsby }\end{array}$ & $\begin{array}{l}\text { 3. Comparison } \\
\text { Mingers and } \\
\text { Brockelsby } \\
\text { (mod) }\end{array}$ & 4. Action \\
\hline $\begin{array}{l}\text { Activity } \\
\text { in each phase }\end{array}$ & $\begin{array}{l}\text { Appreciate } \\
\text { characteristics } \\
\text { of the problem }\end{array}$ & $\begin{array}{c}\text { Select relevant } \\
\text { systems based on: }\end{array}$ & $\begin{array}{l}\text { Analyse } \\
\text { structures and } \\
\text { constraints }\end{array}$ & $\begin{array}{l}\text { Develop predictions } \\
\text { of relevant areas } \\
\text { taking into account: }\end{array}$ & Assess & \begin{tabular}{|c|} 
Compare \\
notional systems \\
with the real \\
world in order to \\
establish: \\
\end{tabular} & Act to \\
\hline \multirow{2}{*}{ Social } & \multicolumn{2}{|c|}{ social practices, power relations } & \multicolumn{2}{|c|}{ distortions, conflicts, interests } & \multicolumn{2}{|c|}{ ways to change existing structures } & $\begin{array}{c}\text { generate } \\
\text { empowerment and } \\
\text { alignment }\end{array}$ \\
\hline & \multicolumn{2}{|c|}{$\begin{array}{l}\text { Interview - Check list- } \\
\text { SSM: Rich picture }\end{array}$} & Workshop & $\begin{array}{l}\text { SSM: Root } \\
\text { Definition }\end{array}$ & \multicolumn{2}{|c|}{$\begin{array}{l}\text { SSM: A } 123 \\
\text { Ideal conceptual model }\end{array}$} & $\begin{array}{l}\text { Workshop- } \\
\text { SSM }\end{array}$ \\
\hline \multirow{2}{*}{ Personal } & \multicolumn{2}{|c|}{ individual beliefs, perceptions } & \multicolumn{2}{|c|}{$\begin{array}{l}\text { differences between perceptions and } \\
\text { rational postures }\end{array}$} & $\begin{array}{l}\text { conceptualizations } \\
\text { constructions }\end{array}$ & and alternative & \begin{tabular}{|l} 
generate \\
predisposition and \\
consensus
\end{tabular} \\
\hline & \multicolumn{2}{|c|}{$\begin{array}{l}\text { Interview - Check list- } \\
\text { SSM: Rich picture }\end{array}$} & $\begin{array}{c}\text { SODA: Mental } \\
\text { Maps - } \\
\text { Process Diagram }\end{array}$ & $\begin{array}{l}\text { SSM: Root } \\
\text { Definition }\end{array}$ & \multicolumn{2}{|c|}{ SSM } & $5 \mathrm{~S}$ \\
\hline \multirow[b]{2}{*}{ Material } & \multicolumn{2}{|c|}{ physical evidences } & causal structures & & \multicolumn{2}{|c|}{ physical and structural alternatives } & \begin{tabular}{|l} 
select $\quad$ and \\
implement suitable \\
alternatives
\end{tabular} \\
\hline & \multicolumn{2}{|c|}{$\begin{array}{l}\text { Interview - Check list- } \\
\text { SSM: Rich picture }\end{array}$} & $\begin{array}{l}\text { Cause-effect } \\
\text { diagram }\end{array}$ & $\begin{array}{l}\text { SSM: Root } \\
\text { Definition }\end{array}$ & \multicolumn{2}{|c|}{$\begin{array}{l}\text { Failure Mode and Effects Analysis } \\
\text { (FMEA) - Lay out - Methods and } \\
\text { times study - hygiene and safety - }\end{array}$} & $\begin{array}{c}\text { Linear } \\
\text { programming - } \\
\text { Multicriteria } \\
\text { decision }\end{array}$ \\
\hline
\end{tabular}

Table 3. Methodologies and tools applied (green) and proposed (yellow) -

Multi methodological / multi paradigmatic practice in OR. Modified from Mingers and Brockelsby (1997) 
In the following paragraphs we analyse the application already made of some of the tools (the development of the whole would greatly exceed the allowed extension), in the different phases, based on the original Mingers and Brockelsby scheme, detailed in table 3.

\subsubsection{Phase 1: Appreciation of the characteristics of the problem from the social, personal and material dimensions}

In order to appreciate the characteristics of the problem in the three dimensions, visits were made to the organization, individual interviews and checklist with key interlocutors. From these, the rich picture of the situation considered problematic was elaborated, Figure 3.

In this first stage a general diagnosis of the organization was made in order to define the problematic situations, both at strategic and management level, to be addressed. The participation of key stakeholders was sought, either because they have the power to make decisions about the problem or because they are directly affected by the decisions to be made. The deputy manager was interviewed. He gives accounting advice to the organization, makes the quotations, oversees the promotion and publicity of the company and has authority over the procurement officer of workshops and purchases, the sales manager and the embroiderer.

As a result of this interview and a checklist, the following were surveyed:

- The characteristics of the organization: as it was mentioned before, it is a small family business dedicated to the preparation and sale of uniforms, with start of activities in 2006. It has five stable members and staff of clothing and embroidery workshop hired according to demand,

- The processes in which they were interested in improving. In terms of strategic management, they expressed interest in carrying out: business diagnostics, as well as technological innovation, process/product management and TICS, indicating that they had defined mission and vision and did not have a manual of functions or quality policies.

- In terms of operations management, they expressed interest in carrying out: Long and medium-term planning, programming and control of projects and resource analysis, indicating that they had defined the organization chart, they did not have a process map, they identified their suppliers and clients and they documented their procedures.

- In terms of quality management, they expressed interest in advance in continuous improvement processes and work in teams' methodology, leaving for a second stage the application of statistical process control and certification with current quality standards, 
indicating that they were not in process of improvement or certification and that they did not apply quality tools.

The main concern of the management was the reduction of costs and the consequent analysis of all the processes that affect them.

Both in the aspects that answered positively and negatively, they expressed their interest in improving them.

From the interview, the check list and the visits to the organization the Rich Picture was elaborated (Figure 3). It shows the hierarchical relationship and the main problems in production and administration areas.

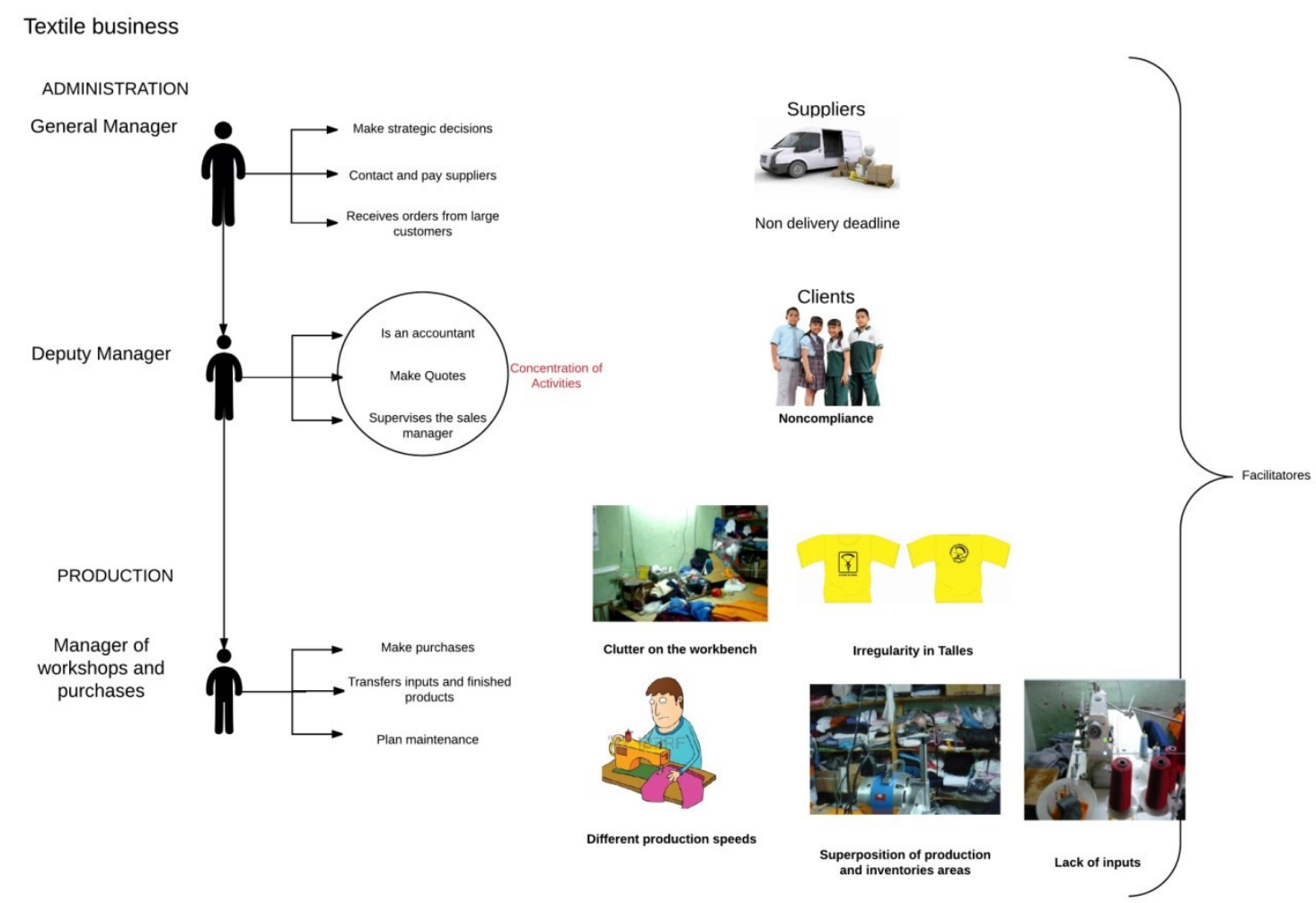

Figure 3. Rich Picture of the Problematic Situation in a SME of the Textile Industry Salta, Argentina

In production area: The team detected deficiencies in the processes related to: the lack of inputs due to planning failures; the incorrect distribution of the machines and inventory areas; the disorder in the work table; the variability of the manufacturing times of each operator; the irregularity in the termination for the same product; and the breach of safety and hygiene standards. Furthermore, during the workshops and interviews, it became apparent that, the head of workshops and purchases were overloaded and seem to concentrate many activities. 
In regard to the Administration Area: Delays were observed with customers, manifested through their complaints or by lost sales. As can be observed in the rich picture there are problems of distribution of the physical space in the sales room, since it is very small. The team noticed that there were inventories of finished products, but also some raw materials, plus the embroidery workshop in a place adjacent to it. We were also informed about the non-compliance of some suppliers, motivated in part by inadequate planning of purchases. Again, the team observed that senior levels of management such as the General and Deputy Manager seem to concentrate lot of responsibilities.

\subsubsection{Phase 2: Analysis of structures and restrictions / Predicate}

For the analysis of structures and restrictions in the three dimensions, an adaptation of the mental maps of SODA, Diagram of processes and Diagram of cause and effect were elaborated.

In this second stage, we sought to structure the problem. Analysing the rich picture, the problematic situations were identified, in a participative process between the members of the organization and the team, which were grouped according to their area: Production or Administration and Sales. Next, we describe the perceived problems in each of these areas.

The area of Production was closely scrutinized and amongst the various problems detected, the team felt that a close analysis of the variability of the manufacturing times of each operator, was necessary. This analysis was carried out suing various OR tools and it is presented below.

Using the Cause - Effect diagram, a classic tool of Quality Management, the different causes that provoke different production times of the garments, were analysed with the participation of those involved. It is expressed schematically in Figure 4.

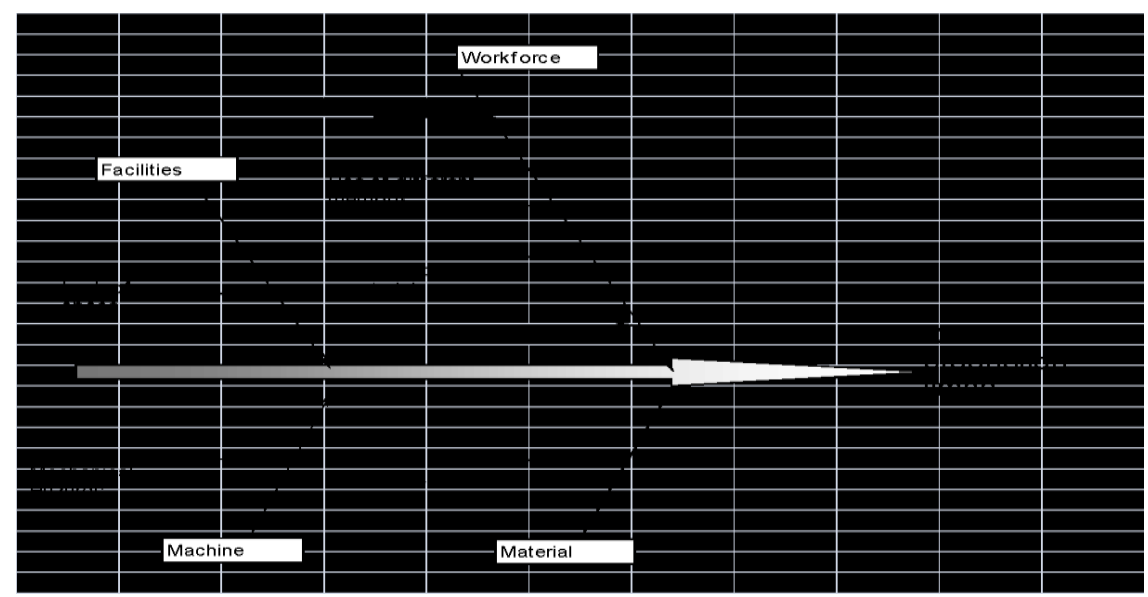

Figure 4. Diagram Cause-Effect of problems in the production area (elaborated with the stakeholders) 
It was observed and agreed that the different production times for the same product, have causes associated with the factors: Facilities, Machines, Labour and Material.

In relation to the facilities, the lack of space was observed, which causes that there were sectors of temporary deposit of clothes in execution, making difficult the task of the workers and the transfer of the production in process. In relation to the Machines, they were stopped due to mechanical damage. For labour, it was observed that some workers were faster than others to develop the activity, that they used different sewing methods, that human failures occurred, which evidenced a lack of training. For the material, it was detected that not all the pieces were cut at the time of preparation, some of them had faults and there were threads of poor quality.

Considering the diversity of causes that motivated the different production times of the operators, their opinions were considered, such as those of the head of the cutting and sewing workshop and the superior instance of the assistant manager, to agree on a weighting of the same, to establish its level of relative importance. A simple method of assigning weight to the causes was designed, allocating the value of 10 to the most important or main criteria, and from 1-5 to the secondary ones. They are detailed in table $\mathrm{N}^{\circ} 4$. Weighting of causes.

\begin{tabular}{|l|l|l|}
\hline Source factor & Criteria & Weight (1-10) \\
\hline \hline Facilities & Lack of Space and Comfort & 5 \\
\hline Machines & Mechanical flaws & 5 \\
\hline \multirow{4}{*}{ Workforce } & Human Faults & 5 \\
\cline { 2 - 3 } & Lack of Training & 10 \\
\cline { 2 - 3 } & Speed of people is different & 10 \\
\cline { 2 - 3 } & Using different sewing methods & 4 \\
\hline Material & Not all pieces are cut at the time of making & 3 \\
\hline
\end{tabular}

Table 4. Assigning weights- causes for the variability of production times

As can be seen in Table 4, the main variables that seem to cause the different production times is the lack of training (which can be worked with appropriate training systems for the task); and the different abilities of workers (difficult factor to control but that can also be improved through training and experience).

In order to tackle the problems in the Administration area, the team gather information from suppliers; this was prompted by the Deputy Manager who mentioned that there were delays (see Rich picture). During the interview, information was compiled from the six suppliers with which the organization usually interacts. Another important problem detected was that both the Deputy 
Manager and the Head Workshop/ Procurement Officer centralize many activities under their responsibility.

\subsubsection{Phase 3: Assessment / Comparison}

For the assessment, in the material dimension, Failure Mode and Effects Analysis (FMEA), lay out ideal vs current lay out, studies of methods and times for real processing times and a revision of the Hygiene and Safety Regulations, were developed. In the Personal and Social dimension, Analysis 1.2 .3 of SSM is planned.

Production

In this stage, problematic situations were prioritized and analysed. Of all the previous problems, it was agreed the selection of those considered priority by those involved and that were also viable both technically and economically. Continuing with the problem of the different times of production and standardization of sizes, an own method of Quality Management, Failure Mode and Effects Analysis (FMEA) was applied, to analyse possible failures in the production process or the product. This tool was applied in its systemic version of processes, since it analyses different operations for the definition of the system under observation. It describes for different functions or items, in this case the inputs of a garment, the potential failure modes that may present, the effects they produce, their potential causes and the methods of control in execution. Then it establishes three indices: Severity of the fault, Occurrence of the same and No detection. All vary from 1 to 10, with 1 being the most favourable condition and 10 the most unfavourable. The multiplication of the three for each potential cause is carried out, corresponding to paying attention to the highest results, since the higher the indicator, the more compromised the situation.

As can be seen in Table 5, the incorrect assembly of the garments, which manifests itself in defective garments and delays in production, has its origin in activity failures; so training and control of it is promoted. The cut of thread that delays the confection has several causes, being the main one the lack of experience of the worker, that will be controlled by means of training and control of results of the same one. Defective and faulty cut fabrics result in producing different fabric measurements for the same size. The team proposed and recommend to closely verify the measurements of the moulds. 


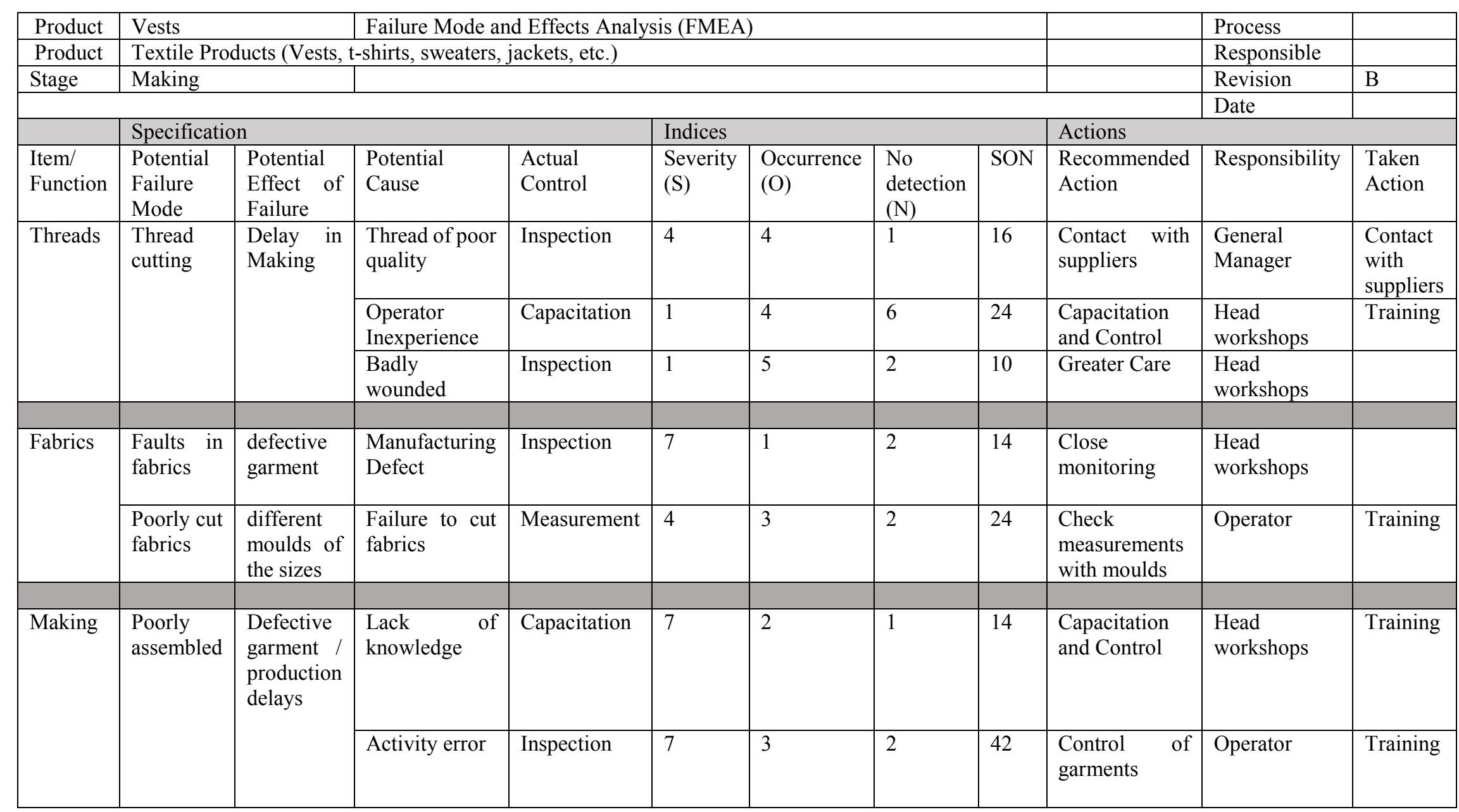

Table 5. Failure Mode and Effects Analysis (FMEA), prepared with stakeholders 
Administration

Regarding the administrative processes, for the problem of lack of evaluation of the suppliers (Problems in the commercial premises) the multicriteria decision methodology was applied; since, according to the manifested by the stakeholders, in the clothing industry it is essential to have a reliable portfolio of suppliers that adequately meets the quality requirements demanded by the customer.

For this reason, an analysis and subsequent evaluation of the company's suppliers was carried out with those involved to determine which are the critical aspects. Different criteria were considered with their corresponding rating scale, assigning an assessment to each provider. For example, for the different types of fabrics, Table 6 , the criteria for evaluating suppliers, agreed upon with those involved, were: Delivery time (C1), Quality (C2), Price (C3), Service (C4), Supplier Distance (C5), Variety of products (C6) and Products Availability (C7).

Scales from 1 to 3 were designed, indicating the highest value, the most favourable situation.

\begin{tabular}{|l|l|l|l|l|l|l|l|}
\hline & Criterion/Supplier & Sedamil & Quelana & Nantex & La General & NordFabril & Glusman \\
\hline C1 & Delivery Time & 1 & 1 & 2 & 3 & 3 & 2 \\
\hline C2 & Quality & 3 & 3 & 3 & 3 & 3 & 2 \\
\hline C3 & Price & 1 & 1 & 2 & 2 & 1 & 2 \\
\hline C4 & Service & 2 & 2 & 2 & 3 & 2 & 2 \\
\hline C5 & Supplier Distance & 1 & 1 & 2 & 2 & 2 & 1 \\
\hline C6 & Variety of products & 2 & 2 & 3 & 3 & 1 & 3 \\
\hline C7 & Product Availability & 1 & 1 & 3 & 3 & 2 & 2 \\
\hline & & 11 & 11 & 17 & 19 & 14 & 14 \\
\hline
\end{tabular}

Table 6. Provider evaluation matrix, prepared with stakeholders

Making the sum of the values assigned to each provider, we can see that Nantex and La General stand out from the rest suppliers, mainly in variety and availability of their products. In this way it was determined which should be the main suppliers that the organization must have to comply with the stipulated dated of orders and the service each one provides, to offer customers confidence and solutions to inconveniences. Finally, with this analysis developed, the company can decide on the right supplier and be able to gain a competitive advantage by knowing the characteristics of its suppliers. 


\subsubsection{Phase 4: Definition of actions to improve the problematic situation}

To take actions, Linear Programming and Multicriteria Decision were applied in the material dimension. In the personal dimension, $5 \mathrm{~S}$ was used and SSM is planned. The latter also foreseen for the social dimension.

The problematic situation was worked at different levels of the organization. In the following paragraphs we describe the improvements that were suggested to be introduced.

Production

For planning failures in production process, it was applied a Linear Programming model. This allowed to determine the production plan for school t-shirts, which minimizes manufacturing costs, considering demand restrictions, production capacity of the workshop and available space of the sales room. The results obtained improved the production plan in execution. This was a work of approximately half a year since the detection of the problematic situation, the taking of data, the modelling, resolution and validation.

For the incorrect distribution of machine and inventory areas, it was developed a lay out study, which indicated the new distribution of the machines in the workshop

For the variability of manufacturing times of each operator and the failures to cut fabrics, operators were trained in cutting and sewing methods

Administration

For the strategic processes, the proposal of the vision and mission of the organization was improved, and a new organizational chart and functions manual was proposed. It contributed to redefining the responsibilities and activities of the general manager, the deputy manager and the head of workshop.

In relation to the non-compliance of some suppliers, multi-criteria decision analysis was applied to determine the best of them. It allowed to establish an administrative process for requesting raw materials

To propose improvements in the problems of distribution, the 5S Rules approach were applied in the commercial area, in the warehouses and in workshops. 5S Rules comprises of: SEIRI (It is Cleared): Eliminate the objects that are not necessary. SEISO (Cleans): Clean the workplace. SEITON (Organized): A place for everything and everything in its place. SEIKTETSU (Standardize): Establish the standards. SHITSUKE (Holds on Time): Maintain standards. These rules were applied in the Commercial office and in Cerrillos Workshop, to establish basic order 
and discipline in the workplace, improve the work environment, eliminate the waste produced by disorder, order the finished and in process products and reduce losses of time due to lack of order.

\section{Conclusions and future research}

In this article we have argued that the current trend in the field of OR is the use of several methodologies, methods and techniques in combination. The article briefly reviews the history of soft methodologies in OR.

Using the Mingers and Brockelsby scheme as a basis, its use is proposed with some modification that rescues Checkland's ideas in the sense that in all systemic intervention it is necessary to discriminate which activities are located in the conceptual world and which in the real world.

The article reports the partial results of a systemic intervention carried out in Salta Argentina, in a SME that operates in the textile sector. The paper informs the use of Soft OR, Hard OR and QM tools, using the original Mingers and Brockelsby framework.

It is interesting to highlight the potential of the systemic approach in light of a real case, such as this textile company. When it was studied with a focus on hard OR and considering the priority of the stakeholders to reduce costs; a problem in production planning was revealed, which could be approached through the development and application of Linear Programming. When it was studied from a systemic focus, different situations could be detected to improve, as well as the causes that produced them, such as the different processing times for the same product or the noncompliance of some suppliers.

The systemic approach, with more active participation of the stakeholders, allowed relating the diverse problematic situations (rich picture) detected, in the different dimensions raised by Mingers and Brockelsby and defining action plans to modify the causes that generate them. This is enhanced, because the same cause, for example the lack of training, affects more than one problematic situation: different manufacturing times (Cause-Effect Diagram) and poorly armed garments (FMEA). That is, if actions are taken to correct this deficiency, it contributes to the solution of more than one problem; criteria suggested to the organization to begin its action plan.

The use of easy-to-understand tools for those involved increases the possibilities of giving continuity to the proposal and allows the organization to continue the improvement plan without the support of the research team. 
Regarding the fieldwork developed, it is important to point out that more tools, than those described here, were applied. In this paper we report a sequence of them as an example of the activities carried out.

This is a project in progress and our current step is to revisit the SME and try to re-apply the Mingers and Brockelsby scheme, but this time with the modification and addition that we propose in this article in point 3 , to separate the real and conceptual worlds, planning a proposal consistent with it. We hope to do these tasks in the near futtre.

\section{References}

Ackermann F, Eden CP. 2011. Strategic Management of Stakeholders: Theory and Practice. Long Range Planning 44:179-196 http://www.elsevier.com/locate/lrp

Castellini MA. 2014. Aporte interdisciplinario a los procesos de gestión en las micro y pequeñas organizaciones de Salta. Revista Ingenio y Desarrollo- Fundación del Consejo Profesional de Ingeniería y Profesiones Afines 3: 66-72.

Castellini MA, Zanazzi, JL, Cabrera GP. 2017. Selecting Working Teams for Information Technology Outsourcing Projects Through a Combination of Methodologies. Pesquisa Operacional 37(1): 67-92.

Checkland P. 1981, 1999. Systems Thinking, Systems Practice. John Wiley and Sons Ltd: Chichester.

Checkland P. 2000. Soft Systems Methodology: A Thirty-Year Retrospective. Systems Research and Behavioral Science 17:11-58.

Eden C, Ackermann F. 2004. Cognitive mapping expert views for policy analysis in the public sector. European Journal of Operational Research 152:615-630

Franco L, Lord E. 2011. Understanding Multi-Methodology: Evaluating the Perceived Impact of Mixing Methods for Group Budgetary Decisions. Omega 39:362-372

Flood RL, Jackson M. 1991. Creative problem solving: total systems intervention. John Wiley and Sons Ltd: Chichester.

Georgiou I. 2008. Making Decisions in the Absence of Clear Facts. European Journal of Operational Research 185: 299-321.

Georgiou I. 2012. Messing About in Transformations: Structured Systemic Planning for Systemic Solutions to Systemic Problems. European Journal of Operational Research 223: 392-406

Habermas J. 1970. Knowledge and interest in Sociological Theory and Philosophical Analysis. Emmet et al, (eds.), Macmillan, London 
Henao F, Franco L. 2016. Unpacking multimethodology: Impacts of a community development intervention. European Journal of Operational Research 253: 681-696. http://dx.doi.org/10.1016/j.ejor.2016.02.044

Jackson MC. 1999. Towards coherent pluralism in management science. Journal of the Operational Research Society 50:12-22.

Jackson MC. 2000. Systems approaches to Management. Plenum, New York

Kotiadis K, Mingers J. 2006. Combining PSMs with hard OR methods: the philosophical and practical challenges. Journal of the Operational Research Society 57: 856-867

Mingers J. 1997a. Multi-paradigm Multimethodology: Towards Theory and Practice and Mixing and Matching Methodologies. In Multimethodology: The theory and Practice of Combining Management Science Methodologies, Mingers J, Gill P (eds.). John Wiley and Sons Ltd: Chichester, 1-14.

Mingers J. 1997b. Towards critical pluralism. In Multimethodology: The theory and Practice of Combining Management Science Methodologies, Mingers J, Gill P (eds.). John Wiley and Sons Ltd: Chichester.

Mingers J, Brocklesby J. 1997. Multimethodology: for Mixing Towards a Framework Methodologies. Omega, Int. J. Mgmt Sci. 25 (5): 489-509.

Mingers J. 1999. A Comparative Characterisation of Management Sciences Methodologies. Systemist 21(2): 81-92.

Mingers J. 2000. Variety is the Spice of Life: Combining Soft and Hard OR/MS Methods. International Transactions in Operational Research 7(6): 673-691.

Mingers J. 2001. Combining IS Research Methods: Towards a Pluralist Methodology Information Systems Research 12: 240-259.

Mingers J, Munro I. 2002. The Use of Multimethodology in Practice - Results of a Survey of Practitioners. Journal of Operational Research Society 53 (4): 369-378. ISSN 0160-5682. $($ doi:10.1057 $=$ palgrave $=$ jors $=2601331)$

Mingers J, White L. 2010. A review of the recent contribution of systems thinking to operational research and management science. European Journal of Operational Research 207: 1147-1161.

Paucar-Caceres A. 2003. Measuring the effect of highly cited papers in OR/Systems journals: a survey of articles citing the work of Checkland and Jackson, Systems Research and Behavioural Science 20: 65-79.

Paucar-Caceres, A. and Jerardino-Wiesenborn, B. (2018). A conceptual Framework for incorporating Maturana onto-epistemology into Checkland's Soft Systems Methodology. $29^{\text {th }}$ European Conference Operational Research, EURO conference, Universidad de Valencia, Spain, July 2018. https://www.euro-online.org/conf/euro29/program

Paucar-Caceres A, Hart D, Roma i Vergés J, Sierra-Lozano D. 2015. Applying soft systems methodology to the practice of managing family businesses in Catalonia. Systems Research and Behavioural Science. Published online in Wiley Online Library DOI:10.1002/sres.2356 
Pollack J. 2009. Multimethodology in series and parallel: strategic planning using hard and soft OR. Journal of the Operational Research Society 60:156-167.

Pontelli D, Conforte J, Zanazzi JL, Castellini MA, Dimitroff M, Massari P. 2014. La gestión de los residuos patógenos en la UNC. Un problema abordado desde las multimetodologías, in Aplicación de Multimetodologías para la gestión y evaluación de sistemas socio-técnicos. Tomo II. Zanazzi JL, Alberto CL, Carignano CE (eds.). Asociación Facultad de Ciencias Económicas Universidad Nacional de Córdoba. 260-288.

Rosenhead, J. (ed.) 1989. Rational Analysis for a Problematic World. John Wiley and Sons Ltd: Chichester.

Rosenhead J, Mingers J. (eds.) 2001. Rational Analysis for a Problematic world revisited. John Wiley and Sons Ltd: Chichester.

Rosenhead J. 2006. Past, present and future of problem structuring methods. Journal of Operational Research Society 57: 759-765.

Silva Barros P, Castellini MA, Belderrain C. 2013. Soft Systems Methodology for improvements in a program of urban food harvest in Aplicación de Multimetodologías para la gestión y evaluación de sistemas socio-técnicos. Parte II. Zanazzi JL, Alberto CL, Carignano CE (eds.). Asociación Facultad de Ciencias Económicas - Universidad Nacional de Córdoba. 145-160.

Small A, Wainwright D. 2014. SSM and Technology Management: Developing Multimethodology through practice. European Journal of Operational Research 233(3): 660673.

Vidal, RVV. 2006. Operational Research: A Multidisciplinary Field. Pesquisa Operacional 26:69-90.

Yolles M. 2010. Exploring complex sociocultural situations through Soft Operational Research. Pesquisa Operacional 30 (2): 345-370. 